\title{
Atributos florísticos e ecológicos de formações arbustivas da Restinga em área-chave para conservação da biodiversidade, Guarapari, ES, Brasil
}

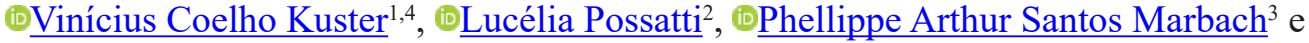 \\ ๑ Márcio Lacerda Lopes Martins ${ }^{3}$
}

Recebido: 23 novembro 2018; aceito: 9 agosto 2019

Como citar: Kuster, V.C., Possatti, L., Marbach, P.A.S. \& Martins, M.L.L. 2019. Atributos florísticos e ecológicos de formações arbustivas da Restinga em área-chave para conservação da biodiversidade, Guarapari, ES, Brasil. Hoehnea 46: e1002018. http://dx.doi.org/10.1590/2236-8906-100/2018.

ABSTRACT - (Floristic and ecological attributes of Restinga shrub formations in key area for biodiversity conservation, Guarapari, Espírito Santo State, Brazil). The water table level has been assuming a prominent role in recent years in studies about the structuring of plant communities in Restinga, which led us to compare the floristic and phytosociological structure between flooded and non-flooded open shrubby formations. The floristic survey and line intercept method were conducted in both the phytophysiognomies. For the phytosociological analysis, two plots of $20 \times 150 \mathrm{~m}$, which were subdivided into five subplots of $20 \times 30 \mathrm{~m}$, were installed in each phytophysiognomym. A total of 147 bushes were evaluated, 49 from the flooded and 98 from the non-flooded formations, representing, on average, areas of $210.78 \mathrm{~m}^{2}$ and $30.45 \mathrm{~m}^{2}$, respectively. The flooded formation showed an average of 4.9 bushes per subplot, while the non-flooded formation showed an average of 9.8. As a total, 100 species from 40 families were found in the two vegetation types, 87 of them in the flooded and 68 in the non-flooded areas. The most representative families were Orchidaceae and Bromeliaceae. We found a high floristic distinction between the vegetation types, suggesting that the water table level affected the structure of plant communities. Keywords: Bromeliaceae, Orchidaceae, Parque Estadual Paulo César Vinha

RESUMO - (Atributos florísticos e ecológicos de formações arbustivas da Restinga em área-chave para conservação da biodiversidade, Guarapari, ES, Brasil). O lençol freático vem assumindo papel de destaque nos últimos anos nos estudos sobre a estrutura das comunidades vegetais na Restinga, o que nos levou a comparar a estrutura florística e fitossociológica entre formações arbustivas abertas inundáveis e não inundáveis. Levantamento florístico e método do intercepto de linha foram realizados em ambas as fitofisionomias. Para a análise fitossociológica foram instaladas duas parcelas de $20 \times 150$ $\mathrm{m}$ em cada fitofisionomia, subdivididas em cinco subparcelas de $20 \times 30 \mathrm{~m}$. Foram amostradas 147 moitas, sendo 49 da formação inundável e 98 da não inundável, representando, respectivamente, $210,78 \mathrm{~m}^{2}$ e $30,45 \mathrm{~m}^{2}$ de área média. A formação inundável apresentou média de 4,9 moitas por subparcela, enquanto a área não inundável 9,8. Foram encontradas 100 espécies para as duas fitofisionomias, distribuídas em 40 famílias, sendo 87 espécies para a área inundável e 68 para a não inundável. As famílias com maior representatividade foram Orchidaceae e Bromeliaceae. Elevada distinção florística foi encontrada entre as fitofisionomias, sugerindo que o nível lençol freático afetou a estrutura das comunidades vegetais. Palavras-chave: Bromeliaceae, Orchidaceae, Parque Estadual Paulo César Vinha

\section{Introdução}

A restinga é um dos ecossistemas associados a Mata Atlântica (Coutinho 2006), geologicamente denominada como qualquer depósito arenoso do litoral brasileiro (Scherer et al. 2005, Assumpção \& Nascimento 2000). É formada por amplas planícies litorâneas arenosas, que foram expostas a partir dos

1. Universidade Federal de Goiás, Regional Jataí, Campus Cidade Universitária, BR 364, km 195, 3800, 75801-615 Jataí, GO, Brasil

2. Universidade Vila Velha, Rua Comissário José Dantas de Melo, 21, Boa Vista, 29102-770 Vila Velha, ES, Brasil

3. Universidade Federal do Recôncavo da Bahia, Rua Ruy Barbosa, 710, Centro, 44380-000 Cruz das Almas, BA, Brasil

4. Autor para correspondência: viniciuskuster@ufg.br 
recuos marinhos, permitindo que fossem colonizados por espécies dos ecossistemas próximos (Pereira \& Assis 2000, Suguio \& Martin 1993). A presença de lagos, o desnível do solo que aproxima ou distancia o lençol freático da superfície, a direção dos ventos, a distância do mar, a formação geológica, as condições climáticas e edáficas são alguns dos fatores que afetam a distribuição da vegetação nas restingas, contribuindo com a organização das comunidades vegetais e das diferentes fitofisionomias (Pereira \& Zambom 1998, Suguio \& Martin 1993).

As fitofisionomias da restinga têm recebido distintas nomenclaturas, desde a estabelecida por Ule (1901) para um trecho de Cabo Frio, no Rio de Janeiro. Pode-se destacar a classificação de Araújo \& Henriques (1984), que propuseram 11 formações vegetais nas restingas brasileiras, sendo elas: halófilapsamófila reptante, dunas, pós-praia, palmae, aberta de Clusia, mata seca, arbustiva fechada inundável, aberta de Ericaceae, floresta periodicamente inundável, brejo herbáceo e floresta permanentemente inundável. Pereira (2003) manteve o número de fitofisionomias, porém alterou as terminologias e as relacionou principalmente com a influência do lençol freático, além de características fisionômicas.

Dentre as formações vegetais, as arbustivas podem ser diferenciadas em abertas e fechadas, sendo as abertas formadas por moitas. As formações abertas contêm elevado número de espécies vegetais, separadas por regiões entre moitas, com predominância de espécies herbáceas e com pouca diversidade (Ribas et al. 1993). As formações arbustivas abertas podem ser classificadas, segundo Araújo \& Henriques (1984), em formação aberta de Ericaceae, com inundação do solo pelo lençol freático, e formação aberta de Clusia, sem inundação pelo lençol freático. De acordo com a classificação proposta por Pereira (2003) e revista por Magnago et al. (2011) tais formações foram denominadas, respectivamente, como arbustiva aberta inundável (FAAI) e arbustiva aberta não inundável (FAANI).

A interferência do lençol freático nas comunidades de restinga foi retratada por autores como Pereira et al. (1992) e Sá (1992), que mostraram a sua influência na estrutura florística de fitofisionomias da Restinga. Almeida Jr. et al. (2009), ao avaliarem o nível de lençol freático em áreas campestres e florestais em uma restinga no sul de Pernambuco, encontraram maior diversidade de plantas herbáceas em áreas campestres não inundáveis. No campo inundável, foi evidenciada baixa diversidade e predominância de espécies típicas de ambientes com solo encharcado. Esses trabalhos retratam alterações na diversidade de espécies, fisionomia e até taxas de nutrientes no solo entre áreas com níveis de influência do lençol freático distintos.

O Espírito Santo abriga uma das maiores áreas preservadas de restinga do Brasil, presentes no Parque Estadual Paulo César Vinha (PEPCV), localizado no município de Guarapari. Nesse parque, Pereira (1990) identificou a formação arbustiva aberta inundável (classificação sensu Pereira 2003) pela presença, nas moitas, do arbusto Humiria balsamifera. $\mathrm{Na}$ formação arbustiva aberta não inundável (classificação sensu Pereira 2003) ocorre a presença marcante de bromélias, que formam um anel no entorno da moita. Vriesea procera e Aechmea nudicaulis apresentam elevada representatividade nessa formação (Pereira 1990).

Face ao exposto, esse estudo objetiva avaliar a estrutura florística e fitossociológica entre formações arbustivas abertas não inundáveis e inundáveis, ambas presentes no Parque Estadual Paulo César Vinha, Guarapari, Espírito Santo, Brasil. Espera-se responder às seguintes questões: 1) As fitofisionomias apresentam heterogeneidade florística e fisionômica? 2) Existem espécies vegetais exclusivas que caracterizam e distinguem as duas fitofisionomias? 3) Quais as espécies vegetais conseguem se desenvolver em fitofisionomias com elevada variação na disponibilidade hídrica no solo?

\section{Material e métodos}

Área de estudo - O Parque Estadual Paulo César Vinha (PEPCV) compreende uma planície litorânea de aproximadamente 1.500 ha em Setiba, município de Guarapari, Estado do Espírito Santo, entre as coordenadas $20^{\circ} 33^{\prime}-20^{\circ} 38^{\prime} \mathrm{S}$ e $40^{\circ} 23^{\prime}-40^{\circ} 26^{\prime} \mathrm{W}$. Segundo o sistema Köppen (1948), o clima é classificado como AW, onde os verões são chuvosos e os invernos secos, com precipitação total anual variando de 900 a $1300 \mathrm{~mm}$. A temperatura média anual é de $23,3^{\circ} \mathrm{C}$, a precipitação média anual é de $1.307 \mathrm{~mm}$ e a umidade relativa média anual de $80 \%$ (Assis et al. 2004).

Segundo a classificação de Pereira (2003), o PEPCV apresenta oito formações vegetacionais diferentes, sendo elas: herbácea não inundável, herbácea inundada, arbustiva fechada não inundável, arbustiva aberta não inundável, arbustiva aberta inundável, floresta não inundável, floresta inundável e floresta 
inundada. Para o presente estudo foram selecionadas duas áreas de formação arbustiva aberta do PEPCV: inundável - FAAI e não inundável - FAANI (figura 1). O afloramento do lençol freático foi observado qualitativamente via piezômetro inserido nos três primeiros metros da superfície do solo, em ambas as fitofisionomias, entre os anos de 2006 e de 2007.

Levantamento florístico e fitossociológico - Para o levantamento florístico foram realizadas coletas mensais de plantas vasculares em fase reprodutiva, entre maio de 2006 a maio de 2007, nas fitofisionomias selecionadas. O material vegetal coletado foi prensado no próprio campo e encaminhado a uma estufa de secagem. Os procedimentos de coleta e de herborização foram conduzidos de acordo com Fidalgo \& Bononi (1989). Material testemunho foi depositado no herbário da Universidade Vila Velha (UVVES), com duplicatas inseridas no herbário da Universidade Federal do Espírito Santo (VIES). A classificação para as famílias segue o proposto por APG IV (2016).
Para efeito da análise da estrutura da vegetação foram selecionadas duas áreas com vegetação preservada dentro das formações arbustivas abertas citadas. Em cada uma das áreas, foram inseridas duas parcelas de $20 \times 150$ metros cada, distantes 100 metros uma da outra, subdivididas em cinco subparcelas de $20 \times 30$ metros $(\mathrm{n}=10$ por área), totalizando 0,6 ha. Dentro das parcelas, as moitas tiveram sua maior e menor largura avaliada, além da altura do maior indivíduo. Essas medidas foram usadas para cálculo da área de cobertura e volume das moitas, sendo o cálculo de volume realizado através do cálculo da elipse:

$$
\frac{\left(\left(\frac{4}{3}\right)_{\times} 3_{x} \pi_{x}\left(\varnothing<{ }_{x} \varnothing>>_{x} h\right)\right)}{2}
$$

Onde: $\pi=3,1415 ; \varnothing<=$ menor eixo da moita; $\varnothing>=$ maior eixo da moita; $h=$ altura.

A análise da estrutura da vegetação foi feita com a utilização do método do intercepto de linha

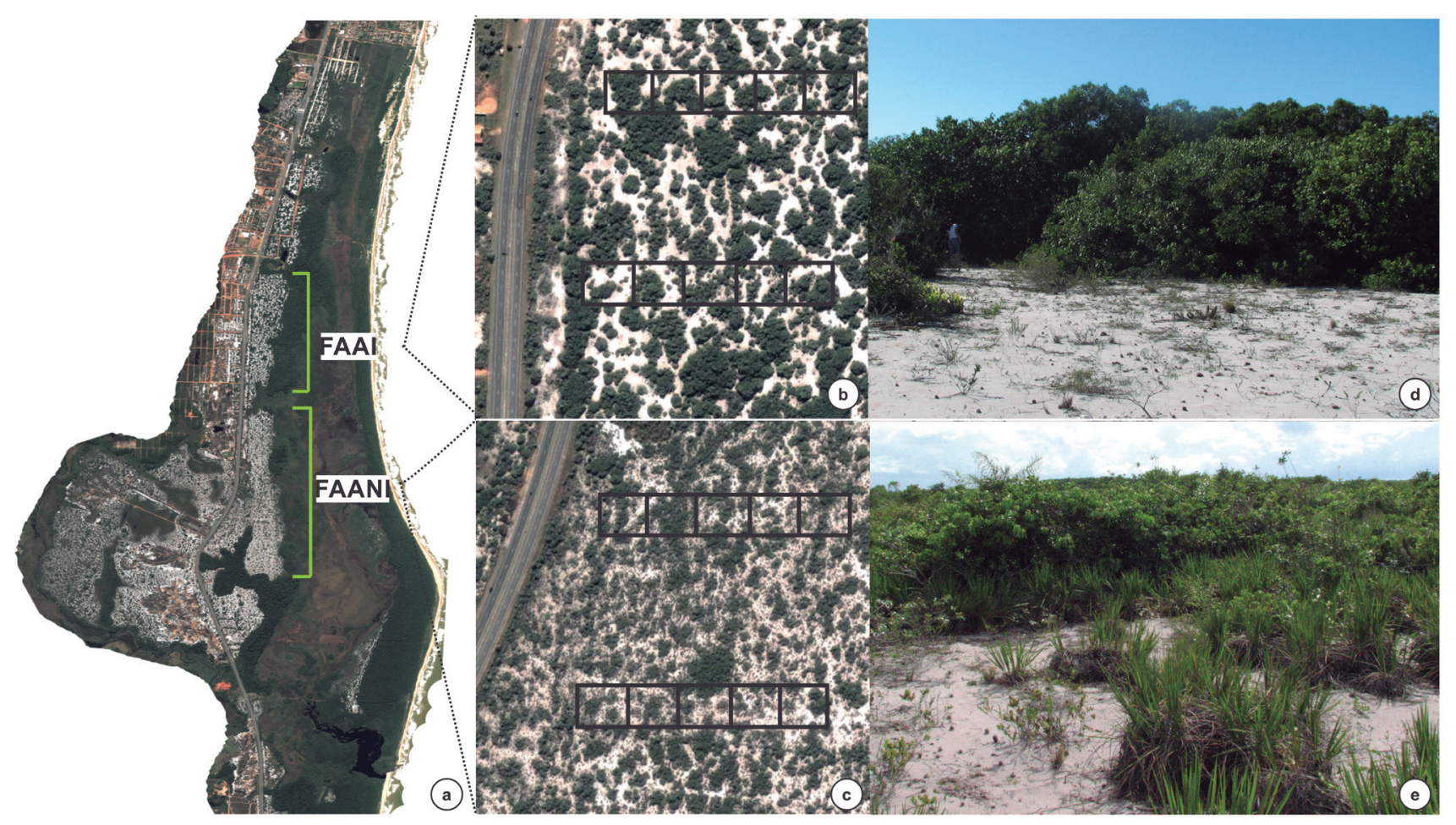

Figura 1. Formações arbustivas abertas inundáveis e não inundáveis amostradas no Parque Estadual Paulo César Vinha, Guarapari, ES, Brasil. A. Visão aérea geral. B. Formação arbustiva aberta inundável com parcelas avaliadas. C. Formação arbustiva aberta não inundável com parcelas avaliadas. D. Estrutura das moitas da formação aberta inundável. E. Estrutura das moitas da formação aberta não inundável. FAAI. Formação arbustiva aberta inundável. FAANI. Formação arbustiva aberta não inundável.

Figure 1. Flooded and non-flooded open shrub formations of the Parque Estadual Paulo César Vinha (State Park), Guarapari City, Espírito Santo State, Brazil. A. General aerial view. B. Flooded open shrub formation with evaluated plots. C. Non-flooded open shrub formation with evaluated plots. D. Structure of the bushes of the flooded open shrub formation. E. Structure of the bushes of the non-flooded shrub formation. FAAI. Flooded open shrub formation. FAANI. Non-flooded open shrub formation. 
descrito por Mueller-Dombois \& Ellenberg (1974). Para tal, um transecto foi posicionado no meio de cada moita, em seu maior diâmetro, sendo mensuradas a cobertura e altura de todos os indivíduos que se projetaram sob o transecto. Foram considerados apenas indivíduos adultos e com valor mínimo de cobertura de um centímetro quadrado. Com esses dados foram quantificados a frequência, a densidade e a cobertura das espécies em cada área. A partir desses resultados, foram calculados os valores de importância absoluta e relativa. A similaridade florística entre as áreas amostradas foi obtida através do cálculo do Coeficiente de Sorensen (S) (Magurran 1988), a partir do programa FITOPAC 1.6.4 (Shepherd 1996). Dendrograma com a distância média (UPGMA) foi montado a partir de médias ponderadas e dos coeficientes de Sorensen, após serem transformados em distância euclidiana quadrada. Em geral, índices de similaridade maiores do que 0,5 são considerados altos.

\section{Resultados}

Características fitofisionômicas - Foram avaliadas 147 moitas, 49 na FAAI e 98 na FAANI, com área média, respectivamente, de $210,78 \mathrm{~m}^{2}$ e $30,45 \mathrm{~m}^{2}$. A porcentagem de cobertura vegetal foi de $79,8 \%$ para a FAAI e de 53,05\% para a FAANI. As análises do nível do lençol freático mostraram a sua maior proximidade a superfície do solo (próximo a três metros) ao longo do ano apenas para a FAAI, porém sem direta inundação da área. FAANI não apresentou lençol freático dentro dos três metros superficiais analisados.

Levantamento florístico - Foi encontrado um total de 100 espécies para as duas áreas, distribuídas em 40 famílias, sendo 87 espécies ocorrentes na FAAI e 68 na FAANI (tabela 1). Dentre essas espécies, 29 são exclusivas da FAAI e 11 da FAANI (tabela 1). As famílias com maior representatividade foram Orchidaceae e Bromeliaceae (sete espécies), Myrtaceae (seis espécies), Rubiaceae, Malpighiaceae e Fabaceae (cinco espécies) (tabelas 1 e 2). As famílias Chrysobalanaceae, Commelinaceae, Ericaceae, Icacinaceae, Nyctaginaceae e Schoepfiaceae ocorreram na FAAI, enquanto Phytolaccaceae teve ocorrência exclusiva na FAANI (tabelas 1 e 2).

Estrutura da vegetação - A família com maior Valor de Importância (VI) na FAAI foi Bromeliaceae, seguida respectivamente pelas famílias Burseraceae, Myrtaceae e Araceae (tabela 2). Na FAANI a família com maior VI foi Myrtaceae, seguida por Burseraceae, Poaceae e Araceae (tabela 2). Araceae apresentou apenas duas espécies, que, no entanto, figuram entre as mais importantes com relação ao VI, ocorrendo no centro das moitas. Anthurium parasiticum é a terceira espécie em VI na FAAI e em sexto na FAANI (tabelas 3 e 4). Anthurium cleistanthum se encontra em $17^{\circ}$ na FAAI e em sexto na FAANI (tabelas 3 e 4).

Em nível específico, Protium icicariba, Vriesea procera, Anthurium parasiticum e Gaylussacia brasiliensis foram as espécies com maior VI na FAAI (tabela 3). Na FAANI, o maior VI foi encontrado para Protium icicariba, Marlierea neuwiedeana, Renvoizea trinii e Smilax rufescens (tabela 4). Em destaque, $R$. trinii apresentou elevado VI, frequência linear relativa (FR) e densidade linear relativa (DLR) na FAANI, no entanto não ocorreu na FAAI (tabelas 4 e 5). Allagoptera arenaria é bem representada nas duas regiões, ocupando em ambas as regiões elevadas posições em relação ao VI (tabelas 4 e 5).

Análise de agrupamento - $\mathrm{O}$ dendrograma identificou três grupos dentre as duas formações arbustivas (figura 2). O grupo 1 apresentou apenas uma das parcelas pertencentes a FAAI, com baixa similaridade em relação aos demais grupos (figura 2). $\mathrm{O}$ grupo 2 foi formado pelas demais parcelas da FAAI, enquanto que o grupo 3 foi composto por todas as parcelas da FAANI (figura 2).

\section{Discussão}

A diferença na estrutura e na riqueza em espécies encontradas nas fitofisionomias abertas inundável (FAAI) e não inundável (FAANI) do Parque Estadual Paulo César Vinha (PEPCV) demonstra elevada variação florística, confirmada pela análise de similaridade, mesmo estando geograficamente próximas. Segundo Montezuma \& Araujo (2007), a água em formações abertas de Restinga pode ser um fator regulador para o desenvolvimento das espécies vegetais, interferindo na estrutura das comunidades, como observado nesse estudo. Young et al. (1995) atribuíram à maior proximidade do lençol freático o crescimento mais favorável para as plantas em ambientes ao longo da região costeira das ilhas da península da Virginia, América do Norte. A proximidade do lençol freático da superfície do solo das parcelas avaliadas na FAAI pode ter contribuído para a maior cobertura vegetal, área e volume das moitas, com espécies vegetais que alcançam até 7,2 metros de altura. Em casos de inundação pelo lençol 
Tabela 1. Lista das espécies vegetais ocorrentes nas formações arbustivas abertas inundáveis e não inundáveis do Parque Estadual Paulo César Vinha, Guarapari, Espírito Santo, Brasil.

Table 1. List of plant species occurring in the flooded and non-flooded open shrub formations of the at Parque Estadual Paulo César Vinha (State Park), Guarapari City, Espírito Santo State, Brazil.

\begin{tabular}{|c|c|c|}
\hline \multirow[b]{2}{*}{ Táxons } & \multicolumn{2}{|c|}{ Formações vegetais } \\
\hline & $\begin{array}{l}\text { Arbustiva aberta } \\
\text { inundável }\end{array}$ & $\begin{array}{l}\text { Arbustiva aberta não } \\
\text { inundável }\end{array}$ \\
\hline \multicolumn{3}{|l|}{ Apocynaceae } \\
\hline Marsdenia montana Malme & $\mathrm{X}$ & $\mathrm{X}$ \\
\hline Peplonia asteria (Vell.) Fontella \& E. A. Schwarz & $\mathrm{X}$ & $\mathrm{X}$ \\
\hline \multicolumn{3}{|l|}{ Araceae } \\
\hline Anthurium cleistanthum G.M.Barroso & $\mathrm{X}$ & $\mathrm{X}$ \\
\hline Anthurium parasiticum (Vell.) Stellfeld & $\mathrm{X}$ & $\mathrm{X}$ \\
\hline \multicolumn{3}{|l|}{ Arecaceae } \\
\hline Allagoptera arenaria (Gomes) Kuntze & $\mathrm{X}$ & $\mathrm{X}$ \\
\hline \multicolumn{3}{|l|}{ Asteraceae } \\
\hline Baccharis reticularia DC. & $\mathrm{X}$ & $\mathrm{X}$ \\
\hline Trichogoniopsis adenantha R.M. King \& H. Rob. & $\mathrm{X}$ & \\
\hline Vernonia fruticulosa Mart. ex DC. & $\mathrm{X}$ & \\
\hline \multicolumn{3}{|l|}{ Bromeliaceae } \\
\hline Aechmea lingulata (L.) Baker & $\mathrm{X}$ & $\mathrm{X}$ \\
\hline Aechmea nudicaulis (L.) Griseb. & $\mathrm{X}$ & $\mathrm{X}$ \\
\hline Tillandsia gardneri Lindl. & $\mathrm{X}$ & $\mathrm{X}$ \\
\hline Tillandsia stricta Sol. ex Ker Gawl. & $\mathrm{X}$ & $\mathrm{X}$ \\
\hline Tillandsia usneoides (L.) L. & $\mathrm{X}$ & \\
\hline Vriesea procera (Mart. ex Schult. f.)Wittm. & $\mathrm{X}$ & $\mathrm{X}$ \\
\hline Bromeliaceae 1 & & $\mathrm{X}$ \\
\hline \multicolumn{3}{|l|}{ Burseraceae } \\
\hline Protium icicariba (DC.) Marchand & $\mathrm{X}$ & $\mathrm{X}$ \\
\hline \multicolumn{3}{|l|}{ Cactaceae } \\
\hline Cereus fernambucensis Lem. & $\mathrm{X}$ & $\mathrm{X}$ \\
\hline Pilosocereus arrabidae (Lem.) Byles \& G. D. Rowley & $\mathrm{X}$ & $\mathrm{X}$ \\
\hline \multicolumn{3}{|l|}{ Celastraceae } \\
\hline Maytenus obtusifolia Mart. & $\mathrm{X}$ & $\mathrm{X}$ \\
\hline \multicolumn{3}{|l|}{ Chrysobalanaceae } \\
\hline Couepia ovalifolia (Schott) Benth. ex Hook.f. & $\mathrm{X}$ & \\
\hline \multicolumn{3}{|l|}{ Clusiaceae } \\
\hline Clusia hilariana Schltdl. & $\mathrm{X}$ & $\mathrm{X}$ \\
\hline Clusia spirictusanctensis G. Mariz \& Weinberg ${ }^{\Delta}$ & $\mathrm{X}$ & $\mathrm{X}$ \\
\hline Rheedia brasiliensis (Mart.) Planch. \& Triana & $\mathrm{X}$ & $\mathrm{X}$ \\
\hline Clusiaceae 1 & & $\mathrm{X}$ \\
\hline \multicolumn{3}{|l|}{ Calophyllaceae } \\
\hline Kielmeyera albopunctata Saddi & $\mathrm{X}$ & \\
\hline
\end{tabular}


Tabela 1 (continuação)

\section{Formações vegetais}

Táxons

Arbustiva aberta inundável

Kielmeyera argentea Choisy $\mathrm{X}$

Kielmeyera membranacea Casar. Arbustiva aberta não inundável

Commelinaceae

Dichorisandra thyrsiflora J.C. Mikan

$\mathrm{X}$

Convolvulaceae

Evolvulus maximiliani Mart. ex Choisy

X

$\mathrm{X}$

Cyperaceae

Cyperus tenuis $\mathrm{Sw}$.

Lagenocarpus verticillatus (Spreng.) T. Koyama \& Maguire

$\mathrm{X}$

$\mathrm{X}$

Ericaceae

Gaylussacia brasiliensis (Spreng.) Meisn.

Leucothoe sp.

$\mathrm{X}$

$\mathrm{X}$

Erythroxylaceae

Erythroxylum subrotundum A. St.-Hil.

$\mathrm{X}$

$\mathrm{X}$

Erythroxylum subsessile (Mart.) O. E. Schulz

Erythroxylum sp.

$\mathrm{X}$

$\mathrm{X}$

Euphorbiaceae

Sebastiania glandulosa (Sw.) Müll.Arg.

$\mathrm{X}$

$\mathrm{X}$

Fabaceae

Acosmium bijugum (Vogel) Yakovlev

Andira nitida Benth.

Chamaecrista cytisoides (Collad.) H.S. Irwin \& Barneby

Chamaecrista ramosa (Vogel) H. S. Irwin \& R. C. Barneby

$\mathrm{X}$

$\mathrm{X}$

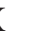

Stylosanthes viscosa Sw.

Humiriaceae

Humiria balsamifera Aubl.

Humiriastrum spiritu-sancti Cuatrec.

$\mathrm{X}$

$\mathrm{X}$

Icacinaceae

Emmotum nitens (Benth.) Miers

X

Lauraceae

Ocotea notata (Nees \& Mart.) Mez

X

$\mathrm{X}$

Lauraceae 1

$\mathrm{X}$

Loranthaceae

Struthanthus sp.

$\mathrm{X}$

X

Lythraceae

Cuphea flava Spreng.

$\mathrm{X}$

X

Malphighiaceae

Byrsonima sericea DC.

Stigmaphyllon paralias A. Juss.

$\mathrm{X}$


Tabela 1 (continuação)

Formações vegetais

Táxons

Arbustiva aberta inundável

Arbustiva aberta não inundável

\section{Malphighiaceae}

Malpighiaceae 1

Malpighiaceae 2

Malpighiaceae 3

Myrtaceae

Eugenia arenaria Cambess.

Marlierea neuwiediana (O.Berg) Nied.

Myrcia acuminatissima O.Berg

Myrcia thyrsoidea O. Berg

Myrciaria floribunda (H.West ex Willd.) O.Berg

Neomitranthes obtusa Sobral \& Zambom ${ }^{\Delta}$

Nyctaginaceae

Guapira opposita (Vell.) Reitz

Guapira pernambucensis (Casar.) Lundell

Nyctaginaceae 1

Ochnaceae

Ouratea cuspidata Engl. ex Gilg.

Schoepfiaceae

Schoepfia brasiliensis A DC.

Orchidaceae

Brassavola flagellaris Barb. Rodr.

Cattleya harrisoniana Bateman ex Lindl. ${ }^{\Delta}$

Cyrtopodium sp.

Eltroplectris sp.

Epidendrum denticulatum Barb. Rodr.

Habenaria leptoceras Hook.

Vanilla chamissonis Klotzsch

Passifloraceae

Passiflora alliacea Barb. Rodr.

Passiflora galbana Mast.

Passiflora haematostigma Mart. ex Mast.

Passiflora mucronata Lam.

Peraceae

Chaetocarpus myrsinites Baill.

Pera glabrata (Schott) Poepp. ex Baill.

Phytolaccaceae

Microtea paniculata Moq.

Poaceae

Paspalum arenarium Schrad.

Renvoizea trinii (Kunth) Zuloaga \& Morrone
$\mathrm{X}$

$\mathrm{X}$

$\mathrm{X}$

$\mathrm{X}$

$\mathrm{X}$

$\mathrm{X}$

$\mathrm{X}$

$\mathrm{X}$

$\mathrm{X}$

$\mathrm{X}$

$\mathrm{X}$

$\mathrm{X}$

$\mathrm{X}$

$\mathrm{X}$

$\mathrm{X}$

$\mathrm{X}$

$\mathrm{X}$

X

X

X

$\mathrm{X}$

$\mathrm{X}$

$\mathrm{X}$

$\mathrm{X}$

$\mathrm{X}$

$\mathrm{X}$

$\mathrm{X}$

$\mathrm{X}$

$\mathrm{X}$

$\mathrm{X}$

X $\quad \mathrm{X}$

X $X$

$\mathrm{X} \quad \mathrm{X}$

$\mathrm{X} \quad \mathrm{X}$

X

X

$\mathrm{X}$

X

$\mathrm{X}$

X 
Tabela 1 (continuação)

\begin{tabular}{|c|c|c|}
\hline \multirow[b]{2}{*}{ Táxons } & \multicolumn{2}{|c|}{ Formações vegetais } \\
\hline & $\begin{array}{l}\text { Arbustiva aberta } \\
\text { inundável }\end{array}$ & $\begin{array}{l}\text { Arbustiva aberta não } \\
\text { inundável }\end{array}$ \\
\hline \multicolumn{3}{|l|}{ Polygonaceae } \\
\hline Coccoloba alnifolia Casar. & $\mathrm{X}$ & \\
\hline Coccoloba arborescens (Vell.) R.A.Howard & $\mathrm{X}$ & $\mathrm{X}$ \\
\hline Coccoloba confusa R.A.Howard & $\mathrm{X}$ & $\mathrm{X}$ \\
\hline \multicolumn{3}{|l|}{ Polypodiaceae } \\
\hline Microgramma vacciniifolia (Langsd. \& Fisch.) Copel. & $\mathrm{X}$ & $\mathrm{X}$ \\
\hline Polypodium brasiliense Poir. & $\mathrm{X}$ & $\mathrm{X}$ \\
\hline \multicolumn{3}{|l|}{ Rubiaceae } \\
\hline Chiococca alba (L.) Hitchc. & $\mathrm{X}$ & $\mathrm{X}$ \\
\hline Emmeorhiza umbellata (Spreng.) K.Schum. & $\mathrm{X}$ & $\mathrm{X}$ \\
\hline Melanopsidium nigrum Colla & & $\mathrm{X}$ \\
\hline Salzmannia nitida DC. & $\mathrm{X}$ & $\mathrm{X}$ \\
\hline Tocoyena bullata (Vell.) Mart. & $\mathrm{X}$ & $\mathrm{X}$ \\
\hline \multicolumn{3}{|l|}{ Sapindaceae } \\
\hline Dodonea sp. & $\mathrm{X}$ & \\
\hline Paullinia weinmanniaefolia Mart. & $\mathrm{X}$ & $\mathrm{X}$ \\
\hline Serjania communis Cambess. & & $\mathrm{X}$ \\
\hline Serjania salzmanniana Schltdl & $\mathrm{X}$ & $\mathrm{X}$ \\
\hline \multicolumn{3}{|l|}{ Sapotaceae } \\
\hline Manilkara subsericea (Mart.) Dubard & $\mathrm{X}$ & $\mathrm{X}$ \\
\hline \multicolumn{3}{|l|}{ Smilacaceae } \\
\hline Smilax rufescens Griseb. & $\mathrm{X}$ & $\mathrm{X}$ \\
\hline \multicolumn{3}{|l|}{ Verbenaceae } \\
\hline Lantana pohliana Schauer & $\mathrm{X}$ & $\mathrm{X}$ \\
\hline
\end{tabular}

${ }^{\Delta}$ Espécies ameaçadas de extinção da Flora do Espírito Santo (Passamani \& Fraga 2005).

Letras "X" marcadas em negrito indicam ocorrência exclusiva das espécies em uma das áreas.

freático, o estabelecimento de certas espécies pode ser limitado, promovendo redução na riqueza vegetal (Magnago et al. 2011). Segundo Montezuma \& Araújo (2007), as formações arbustivas abertas inundáveis são representadas por áreas com lençol freático mais superficiais e por áreas totalmente inundáveis. Deste modo, a superficialidade do lençol freático, sem inundação, pode explicar o maior número de espécies da FAAI, em comparação com a FAANI.

A composição florística das restingas sofre influência dos ecossistemas circunvizinhos (Giaretta et al. 2013, Scherer et al. 2005). Assim, as diferenças verificadas na flora das formações estudadas em comparação com outros ambientes com mesmas condições ambientais devem ser analisadas também sob essa ótica. Similarmente ao Rio de Janeiro, as famílias com maior riqueza para as restingas do Espírito Santo são Fabaceae (73), Myrtaceae (59), Rubiaceae (48), Orchidaceae (44), Cyperaceae (38), Poaceae (36), Bromeliaceae (35), Euphorbiaceae (30) e Asteraceae (30) (Magnago et al. 2011). Para as formações abertas estudadas, encontramos resultados similares, estando às famílias Orchidaceae, Bromeliaceae, Myrtaceae, Rubiaceae e Fabaceae dentre as de maior representatividade. Para uma restinga do Rio Grande do Sul, Myrtaceae também foi considerada uma das mais representativas (Scherer et al. 2005), porém para o estrato herbáceo de uma formação arbustiva aberta da restinga de Jurubatiba, Rio de Janeiro, as famílias mais representativas foram Rubiaceae (cinco), Bromeliaceae, Cactaceae e Fabaceae (quatro), Orchidaceae e Poaceae (três), 
Tabela 2. Parâmetros fitossociológicos das famílias amostradas nas formações arbustivas abertas inundável e não inundável do Parque Estadual Paulo César Vinha, Guarapari, ES, Brasil, em ordem decrescente de Valor de Importância. NE: Número de espécies por família. VI: Valor de Importância Absoluto. VIR (\%): Valor de Importância Relativo.

Table 2. Phytosociological parameters of families sampled in flooded and non-flooded open shrub formations of the Parque Estadual Paulo César Vinha (State Park), Guarapari City, Espírito Santo State, Brazil, in descending order of Importance Value. NE: Number of species per family. VI: Absolute Importance Value. VIR (\%): Relative Importance Value.

\begin{tabular}{|c|c|c|c|c|c|c|c|c|}
\hline \multirow[b]{2}{*}{ Espécies } & \multicolumn{8}{|c|}{ Parâmetros } \\
\hline & FA & $\begin{array}{l}\text { FR } \\
(\%)\end{array}$ & DLA & $\begin{array}{c}\text { DLR } \\
(\%)\end{array}$ & CLA & $\begin{array}{c}\text { CLR } \\
(\%)\end{array}$ & VI & $\begin{array}{l}\text { VIR } \\
(\%)\end{array}$ \\
\hline Protium icicariba & 0,510 & 4,775 & 0,079 & 4,775 & 0,258 & 19,817 & 29,368 & 9,79 \\
\hline Marlierea neuwiediana & 0,744 & 6,972 & 0,115 & 6,972 & 0,132 & 10,160 & 24,104 & 8,03 \\
\hline Renvoizea trinii & 0,602 & 5,635 & 0,093 & 5,635 & 0,156 & 12,014 & 423,284 & 7,76 \\
\hline Smilax rufescens & 0,632 & 5,921 & 0,098 & 5,921 & 0,002 & 0,193 & 12,036 & 4,01 \\
\hline Allagoptera arenaria & 0,438 & 4,107 & 0,068 & 4,107 & 0,047 & 3,653 & 11,867 & 3,96 \\
\hline Anthurium parasiticum & 0,316 & 2,960 & 0,049 & 2,960 & 0,072 & 5,536 & 11,457 & 3,82 \\
\hline Serjania salzmanniana & 0,357 & 3,342 & 0,055 & 3,342 & 0,012 & 0,921 & 7,607 & 2,54 \\
\hline Ocotea notata & 0,224 & 2,101 & 0,034 & 2,101 & 0,036 & 2,802 & 7,005 & 2,34 \\
\hline Myrciaria floribunda & 0,193 & 1,814 & 0,030 & 1,814 & 0,042 & 3,270 & 6,899 & 2,30 \\
\hline Ouratea cuspidata & 0,316 & 2,960 & 0,049 & 2,960 & 0,011 & 0,883 & 6,805 & 2,27 \\
\hline Chaetocarpus myrsinites & 0,163 & 1,528 & 0,025 & 1,528 & 0,048 & 3,715 & 6,772 & 2,26 \\
\hline Pilosocereus arrabidae & 0,316 & 2,960 & 0,049 & 2,960 & 0,010 & 0,784 & 6,705 & 2,24 \\
\hline Peplonia asteria & 0,336 & 3,151 & 0,052 & 3,151 & 0,000 & 0,052 & 6,356 & 2,12 \\
\hline Struthanthus sp, & 0,336 & 3,151 & 0,052 & 3,151 & 0,000 & 0,040 & 6,343 & 2,11 \\
\hline Kielmeyera membranacea & 0,071 & 0,668 & 0,011 & 0,668 & 0,063 & 4,861 & 6,198 & 2,07 \\
\hline Passiflora alliacea & 0,326 & 3,056 & 0,050 & 3,056 & 0,000 & 0,009 & 6,122 & 2,04 \\
\hline Anthurium cleistanthum & 0,204 & 1,910 & 0,031 & 1,910 & 0,030 & 2,301 & 6,121 & 2,04 \\
\hline Cereus fernambucensis & 0,316 & 2,960 & 0,049 & 2,960 & 0,001 & 0,110 & 6,032 & 2,01 \\
\hline Coccoloba arborescens & 0,204 & 1,910 & 0,031 & 1,910 & 0,028 & 2,204 & 6,025 & 2,01 \\
\hline Cyperus tenuis & 0,275 & 2,578 & 0,042 & 2,578 & 0,008 & 0,636 & 5,794 & 1,93 \\
\hline Clusia spiritu-sanctensis & 0,163 & 1,528 & 0,025 & 1,528 & 0,028 & 2,162 & 5,218 & 1,74 \\
\hline Melanopsidium nigrum & 0,163 & 1,528 & 0,025 & 1,528 & 0,023 & 1,827 & 4,883 & 1,63 \\
\hline Rheedia brasiliensis & 0,163 & 1,528 & 0,025 & 1,528 & 0,015 & 1,220 & 4,276 & 1,43 \\
\hline Clusia hilariana & 0,163 & 1,528 & 0,025 & 1,528 & 0,014 & 1,144 & 4,200 & 1,40 \\
\hline Coccoloba confusa & 0,183 & 1,719 & 0,028 & 1,719 & 0,008 & 0,667 & 4,105 & 1,37 \\
\hline Lantana pohliana & 0,163 & 1,528 & 0,025 & 1,528 & 0,006 & 0,482 & 3,538 & 1,18 \\
\hline Baccharis reticularia & 0,153 & 1,432 & 0,023 & 1,432 & 0,005 & 0,398 & 3,263 & 1,09 \\
\hline Vriesea procera & 0,091 & 0,859 & 0,014 & 0,859 & 0,019 & 1,497 & 3,216 & 1,07 \\
\hline Evolvulus maximiliani & 0,163 & 1,528 & 0,025 & 1,528 & 0,001 & 0,107 & 3,163 & 1,05 \\
\hline Myrcia acuminatissima & 0,051 & 0,477 & 0,007 & 0,477 & 0,023 & 1,800 & 2,755 & 0,92 \\
\hline Passiflora haematostigma & 0,132 & 1,241 & 0,020 & 1,241 & 0,000 & 0,009 & 2,493 & 0,83 \\
\hline Malphighiaceae 1 & 0,071 & 0,668 & 0,011 & 0,668 & 0,011 & 0,866 & 2,204 & 0,73 \\
\hline Cyrtopodium sp, & 0,091 & 0,859 & 0,014 & 0,859 & 0,005 & 0,386 & 2,105 & 0,70 \\
\hline Epidendrum denticulatum & 0,102 & 0,955 & 0,015 & 0,955 & 0,001 & 0,146 & 2,056 & 0,69 \\
\hline Microtea paniculata & 0,102 & 0,955 & 0,015 & 0,955 & 0,000 & 0,002 & 1,912 & 0,64 \\
\hline Tillandsia gardneri & 0,081 & 0,764 & 0,012 & 0,764 & 0,004 & 0,348 & 1,876 & 0,63 \\
\hline
\end{tabular}


Tabela 2 (continuação)

\begin{tabular}{|c|c|c|c|c|c|c|c|c|}
\hline \multirow[b]{2}{*}{ Espécies } & \multicolumn{8}{|c|}{ Parâmetros } \\
\hline & FA & $\begin{array}{l}\text { FR } \\
(\%)\end{array}$ & DLA & $\begin{array}{c}\text { DLR } \\
(\%)\end{array}$ & CLA & $\begin{array}{c}\text { CLR } \\
(\%)\end{array}$ & VI & $\begin{array}{l}\text { VIR } \\
(\%)\end{array}$ \\
\hline Manilkara subsericea & 0,061 & 0,573 & 0,009 & 0,573 & 0,006 & 0,465 & 1,611 & 0,54 \\
\hline Paullinia weinmanniaefolia & 0,081 & 0,764 & 0,012 & 0,764 & 0,000 & 0,051 & 1,579 & 0,53 \\
\hline Maytenus obtusifolia & 0,081 & 0,764 & 0,012 & 0,764 & 0,000 & 0,039 & 1,567 & 0,52 \\
\hline Cuphea flava & 0,081 & 0,764 & 0,012 & 0,764 & 0,000 & 0,014 & 1,542 & 0,51 \\
\hline Erythroxylum subrotundum & 0,061 & 0,573 & 0,009 & 0,573 & 0,004 & 0,312 & 1,459 & 0,49 \\
\hline Andira nitida & 0,071 & 0,668 & 0,011 & 0,668 & 0,000 & 0,068 & 1,405 & 0,47 \\
\hline Tocoyena bullata & 0,051 & 0,477 & 0,007 & 0,477 & 0,005 & 0,445 & 1,400 & 0,47 \\
\hline Aechmea lingulata & 0,010 & 0,095 & 0,001 & 0,095 & 0,015 & 1,198 & 1,389 & 0,46 \\
\hline Aechmea nudicaulis & 0,040 & 0,382 & 0,006 & 0,382 & 0,007 & 0,580 & 1,344 & 0,45 \\
\hline Polypodium brasiliense & 0,051 & 0,477 & 0,007 & 0,477 & 0,003 & 0,258 & 1,213 & 0,40 \\
\hline Emmeorhiza umbellata & 0,061 & 0,573 & 0,009 & 0,573 & 0,000 & 0,024 & 1,170 & 0,39 \\
\hline Passiflora mucronata & 0,061 & 0,573 & 0,009 & 0,573 & 0,000 & 0,004 & 1,151 & 0,38 \\
\hline Byrsonima sericea & 0,040 & 0,382 & 0,006 & 0,382 & 0,005 & 0,381 & 1,145 & 0,38 \\
\hline Stigmaphyllon paralias & 0,051 & 0,477 & 0,007 & 0,477 & 0,001 & 0,135 & 1,090 & 0,36 \\
\hline Passiflora galbana & 0,051 & 0,477 & 0,007 & 0,477 & 0,000 & 0,058 & 1,013 & 0,34 \\
\hline Sebastiania glandulosa & 0,040 & 0,382 & 0,006 & 0,382 & 0,000 & 0,071 & 0,835 & 0,28 \\
\hline Humiria balsamifera & 0,010 & 0,095 & 0,001 & 0,095 & 0,007 & 0,566 & 0,757 & 0,25 \\
\hline Microgramma vacciniifolia & 0,020 & 0,191 & 0,003 & 0,191 & 0,004 & 0,365 & 0,747 & 0,25 \\
\hline Chiococca alba & 0,030 & 0,286 & 0,004 & 0,286 & 0,000 & 0,049 & 0,623 & 0,21 \\
\hline Marsdenia montana & 0,030 & 0,286 & 0,004 & 0,286 & 0,000 & 0,003 & 0,576 & 0,19 \\
\hline Habenaria leptoceras & 0,020 & 0,191 & 0,003 & 0,191 & 0,002 & 0,149 & 0,531 & 0,18 \\
\hline Stylosanthes viscosa & 0,020 & 0,191 & 0,003 & 0,191 & 0,001 & 0,093 & 0,475 & 0,16 \\
\hline Clusiaceae 1 & 0,010 & 0,095 & 0,001 & 0,095 & 0,003 & 0,247 & 0,438 & 0,15 \\
\hline Chamaecrista cytisoides & 0,010 & 0,095 & 0,001 & 0,095 & 0,002 & 0,153 & 0,344 & 0,11 \\
\hline Vanilla chamissonis & 0,010 & 0,095 & 0,001 & 0,095 & 0,001 & 0,112 & 0,303 & 0,10 \\
\hline Malpighiaceae 2 & 0,010 & 0,095 & 0,001 & 0,095 & 0,001 & 0,075 & 0,266 & 0,09 \\
\hline Salzmannia nitida & 0,010 & 0,095 & 0,001 & 0,095 & 0,001 & 0,074 & 0,265 & 0,09 \\
\hline Bromeliaceae 1 & 0,010 & 0,095 & 0,001 & 0,095 & 0,000 & 0,058 & 0,249 & 0,08 \\
\hline Eltroplectris sp. & 0,010 & 0,095 & 0,001 & 0,095 & 0,000 & 0,012 & 0,203 & 0,07 \\
\hline Tillandsia stricta & 0,010 & 0,095 & 0,001 & 0,095 & 0,000 & 0,011 & 0,202 & 0,07 \\
\hline Malpighiaceae 3 & 0,010 & 0,095 & 0,001 & 0,095 & 0,000 & 0,020 & 0,211 & 0,07 \\
\hline Acosmium bijugum & 0,010 & 0,095 & 0,001 & 0,095 & 0,000 & 0,001 & 0,192 & 0,06 \\
\hline
\end{tabular}

Araceae, Convolvulaceae e Solanaceae (dois) (Pereira et al. 2004). Esses resultados indicam uma predominância de espécies de Myrtaceae relacionada a estratos arbustivos e arbóreos.

Para Pereira (1990) e Montezuma \& Araujo (2007), a ocorrência de Humiria balsamifera caracteriza a FAAI, estando entre as espécies com maior VI. No presente estudo, esta espécie ocorreu em ambas as fitofisionomias avaliadas, porém com maiores valores na FAAI (FAAI: $32^{\text {a }}$ posição; FAANI: $53^{\text {a }}$ posição), o que confirma sua representatividade em formações inundáveis. Protium icicariba foi a espécie com maior VI nas duas fitofisionomias, apresentando-se como a principal espécie das moitas, principalmente as de pequeno porte, o que demonstra sua propensão em habitar ambientes com níveis discrepantes de água no solo. Segundo Pereira et al. (2004), P. icicariba também atua como uma das espécies características para as restingas do Parque Estadual do Rio da Onça, em Matinhos, no Paraná, e 
Tabela 3. Parâmetros fitossociológicos das espécies amostradas na formação arbustiva aberta inundável do Parque Estadual Paulo César Vinha, Guarapari, Espírito Santo, Brasil, em ordem decrescente de Valor de Importância. FA (\%)-(\%): Frequência absoluta. FR (\%)-(\%): Frequência relativa. DLA (ind.ha-1): Densidade linear absoluta. DLR (\%)-(\%): Densidade linear relativa. CLA $\left(\mathrm{m}^{2} \cdot \mathrm{ha}^{-1}\right)$ : Cobertura linear absoluta. CLR (\%): Cobertura linear relativa. VI: Valor de Importância. VIR (\%)-(\%): Valor de Importância relativo.

Table 3. Phytosociological parameters of species sampled in the flooded open shrub formation of the Parque Estadual Paulo César Vinha (State Park), Guarapari City, Espírito Santo State, Brazil, in descending order of Importance Value. FA: Absolute Frequency. FR (\%)-(\%): Relative Frequency. DLA (ind.ha $\left.{ }^{-1}\right)$ : Linear density absolute. DLR (\%)-(\%): Linear relative density. CLA $\left(\mathrm{m}^{2} \cdot \mathrm{ha}^{-1}\right)$ : Linear coverage absolute. CLR (\%)-(\%): Linear coverage relative. VI: Importance Value. VIR (\%)-(\%): Relative Importance Value.

\begin{tabular}{|c|c|c|c|c|c|c|c|c|}
\hline \multirow{2}{*}{ Espécies } & \multicolumn{8}{|c|}{ Parâmetros } \\
\hline & FA & FR(\%) & DLA & DLR(\%) & CLA & CLR(\%) & VI & $\operatorname{VIR}(\%)$ \\
\hline Protium icicariba & 0,428 & 2,713 & 0,539 & 25,116 & 0,502 & 8,382 & 36,211 & 12,07 \\
\hline Vriesea procera & 0,836 & 5,297 & 0,154 & 7,208 & 0,568 & 9,486 & 21,992 & 7,33 \\
\hline Anthurium parasiticum & 0,510 & 3,229 & 0,037 & 1,745 & 0,518 & 8,641 & 13,617 & 4,54 \\
\hline Gaylussacia brasiliensis & 0,387 & 2,454 & 0,093 & 4,338 & 0,171 & 2,859 & 9,652 & 3,22 \\
\hline Marlierea neuwiediana & 0,510 & 3,230 & 0,084 & 3,928 & 0,134 & 2,241 & 9,400 & 3,13 \\
\hline Chaetocarpus myrsinites & 0,448 & 2,842 & 0,080 & 3,769 & 0,163 & 2,729 & 9,341 & 3,11 \\
\hline Tillandsia gardneri & 0,469 & 2,971 & 0,021 & 0,981 & 0,303 & 5,068 & 9,020 & 3,01 \\
\hline Clusia hilariana & 0,204 & 1,291 & 0,113 & 5,293 & 0,132 & 2,209 & 8,794 & 2,93 \\
\hline Allagoptera arenaria & 0,448 & 2,842 & 0,048 & 2,255 & 0,114 & 1,916 & 7,014 & 2,34 \\
\hline Ocotea nonata & 0,326 & 2,067 & 0,058 & 2,726 & 0,128 & 2,144 & 6,937 & 2,31 \\
\hline Aechmea lingulata & 0,183 & 1,162 & 0,067 & 3,148 & 0,140 & 2,339 & 6,650 & 2,22 \\
\hline Emmotum nitens & 0,163 & 1,033 & 0,101 & 4,730 & 0,031 & 0,519 & 6,284 & 2,09 \\
\hline Smilax rufescens & 0,489 & 3,100 & 0,001 & 0,087 & 0,185 & 3,086 & 6,274 & 2,59 \\
\hline Maytenus obtusifolia & 0,285 & 1,808 & 0,047 & 2,207 & 0,132 & 2,209 & 6,225 & 2,08 \\
\hline Manilkara subsericea & 0,408 & 2,583 & 0,033 & 1,558 & 0,120 & 2,014 & 6,156 & 2,05 \\
\hline Tillandsia stricta & 0,428 & 2,713 & 0,009 & 0,451 & 0,163 & 2,729 & 5,894 & 1,96 \\
\hline Anthurium cleistanthum & 0,244 & 1,550 & 0,028 & 1,333 & 0,151 & 2,534 & 5,417 & 1,81 \\
\hline Neomitranthes obtusa & 0,306 & 1,938 & 0,038 & 1,775 & 0,085 & 1,429 & 5,142 & 1,71 \\
\hline Cyperus tenuis & 0,448 & 2,842 & 0,015 & 0,730 & 0,054 & 0,909 & 4,482 & 1,49 \\
\hline Rheedia brasiliensis & 0,204 & 1,292 & 0,037 & 1,727 & 0,081 & 1,364 & 4,383 & 1,46 \\
\hline Pilosocereus arrabidae & 0,285 & 1,808 & 0,013 & 0,639 & 0,101 & 1,689 & 4,137 & 1,38 \\
\hline Clusia spiritu-sanctensis & 0,265 & 1,679 & 0,033 & 1,572 & 0,035 & 0,584 & 3,837 & 1,28 \\
\hline Guapira opposita & 0,142 & 0,904 & 0,043 & 2,028 & 0,038 & 0,649 & 3,582 & 1,19 \\
\hline Chiococca alba & 0,224 & 1,421 & 0,020 & 0,971 & 0,066 & 1,104 & 3,496 & 1,17 \\
\hline Coccoloba arborescens & 0,244 & 1,550 & 0,008 & 0,412 & 0,085 & 1,429 & 3,391 & 1,13 \\
\hline Cereus fernambucensis & 0,224 & 1,421 & 0,004 & 0,197 & 0,085 & 1,429 & 3,048 & 1,02 \\
\hline Coccoloba confusa & 0,224 & 1,421 & 0,011 & 0,519 & 0,062 & 1,039 & 2,979 & 0,99 \\
\hline Myrcia acuminatissima & 0,142 & 0,904 & 0,026 & 1,211 & 0,042 & 0,714 & 2,830 & 0,94 \\
\hline Aechmea nudicaulis & 0,142 & 0,904 & 0,012 & 0,561 & 0,074 & 1,234 & 2,700 & 0,90 \\
\hline Myrciaria floribunda & 0,020 & 0,129 & 0,001 & 0,085 & 0,003 & 0,065 & 0,279 & 0,09 \\
\hline Vanilla chamissonis & 0,183 & 1,162 & 0,002 & 0,128 & 0,077 & 1,299 & 2,591 & 0,86 \\
\hline Humiria balsamifera & 0,081 & 0,516 & 0,027 & 1,287 & 0,046 & 0,779 & 2,584 & 0,86 \\
\hline Erythroxylum subrotundum & 0,306 & 1,938 & 0,003 & 0,138 & 0,027 & 0,454 & 2,531 & 0,84 \\
\hline
\end{tabular}


Tabela 3 (continuação)

\begin{tabular}{|c|c|c|c|c|c|c|c|c|}
\hline \multirow{2}{*}{ Espécies } & \multicolumn{8}{|c|}{ Parâmetros } \\
\hline & FA & $\mathrm{FR}(\%)$ & DLA & $\operatorname{DLR}(\%)$ & CLA & CLR(\%) & VI & $\operatorname{VIR}(\%)$ \\
\hline Humiriastrum spiritu-sancti & 0,040 & 0,258 & 0,034 & 1,603 & 0,038 & 0,649 & 2,511 & 0,84 \\
\hline Passiflora aliacea & 0,285 & 1,808 & 0,000 & 0,016 & 0,035 & 0,584 & 2,409 & 0,80 \\
\hline Coccoloba alnifolia & 0,081 & 0,516 & 0,035 & 1,630 & 0,009 & 0,162 & 2,310 & 0,77 \\
\hline Peplonia asteria & 0,224 & 1,421 & 0,000 & 0,023 & 0,050 & 0,844 & 2,289 & 0,76 \\
\hline Polypodium brasiliense & 0,265 & 1,679 & 0,001 & 0,075 & 0,027 & 0,454 & 2,209 & 0,74 \\
\hline Stigmaphyllon paralias & 0,183 & 1,162 & 0,006 & 0,313 & 0,038 & 0,649 & 2,125 & 0,71 \\
\hline Paullinia weinmanniaefolia & 0,102 & 0,645 & 0,006 & 0,325 & 0,066 & 1,104 & 2,076 & 0,69 \\
\hline Epidendrum denticulatum & 0,183 & 1,162 & 0,002 & 0,109 & 0,042 & 0,714 & 1,987 & 0,66 \\
\hline Erythroxylum sp. & 0,244 & 1,550 & 0,002 & 0,110 & 0,011 & 0,194 & 1,856 & 0,62 \\
\hline Kielmeyera albopunctata & 0,102 & 0,645 & 0,011 & 0,520 & 0,035 & 0,584 & 1,751 & 0,58 \\
\hline Dichorisandra thyrsiflora & 0,102 & 0,645 & 0,005 & 0,274 & 0,044 & 0,747 & 1,667 & 0,56 \\
\hline Passiflora galbana & 0,204 & 1,291 & 0,000 & 0,035 & 0,019 & 0,324 & 1,652 & 0,55 \\
\hline Evolvulus maximiliani & 0,142 & 0,904 & 0,003 & 0,141 & 0,031 & 0,519 & 1,565 & 0,52 \\
\hline Ouratea cuspidata & 0,102 & 0,645 & 0,009 & 0,431 & 0,027 & 0,454 & 1,532 & 0,51 \\
\hline Tocoyena bullata & 0,122 & 0,775 & 0,004 & 0,229 & 0,019 & 0,324 & 1,329 & 0,44 \\
\hline Kielmeyera argentea & 0,102 & 0,645 & 0,007 & 0,372 & 0,017 & 0,292 & 1,310 & 0,44 \\
\hline Passiflora haematostigma & 0,142 & 0,904 & 0,000 & 0,009 & 0,021 & 0,357 & 1,271 & 0,42 \\
\hline Nyctaginaceae 1 & 0,163 & 1,033 & 0,002 & 0,101 & 0,007 & 0,129 & 1,265 & 0,42 \\
\hline Myrcia acuminatissima & 0,081 & 0,516 & 0,009 & 0,419 & 0,019 & 0,324 & 1,260 & 0,42 \\
\hline Guapira pernambucensis & 0,081 & 0,516 & 0,011 & 0,515 & 0,011 & 0,194 & 1,227 & 0,41 \\
\hline Cyrtopodium sp. & 0,081 & 0,516 & 0,002 & 0,123 & 0,031 & 0,519 & 1,160 & 0,39 \\
\hline Marsdenia montana & 0,122 & 0,775 & 0,000 & 0,009 & 0,021 & 0,357 & 1,142 & 0,38 \\
\hline Trichogoniopsis adenantha & 0,081 & 0,516 & 0,003 & 0,162 & 0,023 & 0,389 & 1,069 & 0,36 \\
\hline Andira nitida & 0,081 & 0,516 & 0,004 & 0,231 & 0,015 & 0,259 & 1,008 & 0,34 \\
\hline Myrciaria floribunda & 0,081 & 0,516 & 0,002 & 0,109 & 0,019 & 0,324 & 0,951 & 0,32 \\
\hline Malpighiaceae 1 & 0,061 & 0,387 & 0,005 & 0,234 & 0,011 & 0,194 & 0,816 & 0,27 \\
\hline Lantana pohliana & 0,061 & 0,387 & 0,002 & 0,118 & 0,015 & 0,259 & 0,766 & 0,26 \\
\hline Tillandsia usneoides & 0,061 & 0,387 & 0,002 & 0,118 & 0,015 & 0,259 & 0,766 & 0,26 \\
\hline Struthanthus sp. & 0,081 & 0,516 & 0,000 & 0,005 & 0,011 & 0,194 & 0,717 & 0,24 \\
\hline Malpighiaceae 2 & 0,020 & 0,129 & 0,007 & 0,368 & 0,007 & 0,129 & 0,627 & 0,21 \\
\hline Pera glabrata & 0,020 & 0,129 & 0,009 & 0,440 & 0,001 & 0,032 & 0,601 & 0,20 \\
\hline Brassavola flagellaris & 0,061 & 0,387 & 0,001 & 0,056 & 0,007 & 0,129 & 0,573 & 0,19 \\
\hline Microgramma vacciniifolia & 0,061 & 0,387 & 0,000 & 0,003 & 0,007 & 0,129 & 0,521 & 0,17 \\
\hline Salzmannia nitida & 0,040 & 0,258 & 0,002 & 0,107 & 0,007 & 0,129 & 0,495 & 0,17 \\
\hline Emmeorhiza umbellata & 0,040 & 0,258 & 0,000 & 0,005 & 0,011 & 0,194 & 0,458 & 0,15 \\
\hline Couepia ovalifolia & 0,020 & 0,129 & 0,004 & 0,218 & 0,003 & 0,064 & 0,412 & 0,14 \\
\hline Serjania salzmanniana & 0,040 & 0,258 & 0,000 & 0,021 & 0,007 & 0,129 & 0,410 & 0,14 \\
\hline Lagenocarpus verticillatus & 0,040 & 0,258 & 0,000 & 0,019 & 0,007 & 0,129 & 0,408 & 0,14 \\
\hline Paspalum arenarium & 0,040 & 0,258 & 0,000 & 0,011 & 0,007 & 0,129 & 0,400 & 0,13 \\
\hline Schoepfia brasiliensis & 0,020 & 0,129 & 0,003 & 0,168 & 0,003 & 0,064 & 0,362 & 0,12 \\
\hline
\end{tabular}


Tabela 3 (continuação)

\begin{tabular}{lcccccccc}
\hline \multirow{2}{*}{ Espécies } & \multicolumn{7}{c}{ Parâmetros } \\
\cline { 2 - 8 } & FA & FR(\%) & DLA & DLR(\%) & CLA & CLR(\%) & VI & VIR(\%) \\
\hline Lauraceae 1 & 0,020 & 0,129 & 0,001 & 0,090 & 0,007 & 0,129 & 0,349 & 0,12 \\
Dodonea sp. & 0,040 & 0,258 & 0,000 & 0,026 & 0,003 & 0,064 & 0,349 & 0,12 \\
Chamaecrista ramosa & 0,040 & 0,258 & 0,000 & 0,007 & 0,003 & 0,064 & 0,330 & 0,11 \\
Passiflora mucronata & 0,040 & 0,258 & 0,000 & 0,001 & 0,003 & 0,064 & 0,325 & 0,11 \\
Sebastiania glandulosa & 0,020 & 0,129 & 0,001 & 0,077 & 0,003 & 0,064 & 0,271 & 0,09 \\
Leucothoe sp. & 0,020 & 0,129 & 0,001 & 0,058 & 0,003 & 0,064 & 0,253 & 0,08 \\
Byrsonima sericea & 0,020 & 0,129 & 0,000 & 0,046 & 0,003 & 0,064 & 0,240 & 0,08 \\
Cuphea flava & 0,020 & 0,129 & 0,000 & 0,025 & 0,003 & 0,064 & 0,219 & 0,07 \\
Eugenia arenaria & 0,020 & 0,129 & 0,000 & 0,020 & 0,003 & 0,064 & 0,215 & 0,07 \\
Baccharis reticularia & 0,020 & 0,129 & 0,000 & 0,018 & 0,003 & 0,064 & 0,212 & 0,07 \\
Malpighiaceae 3 & 0,020 & 0,129 & 0,000 & 0,017 & 0,003 & 0,064 & 0,211 & 0,07 \\
Habenaria leptoceras & 0,020 & 0,129 & 0,000 & 0,014 & 0,003 & 0,064 & 0,208 & 0,07 \\
Cattleya harrisoniana & 0,020 & 0,129 & 0,000 & 0,009 & 0,003 & 0,064 & 0,204 & 0,07 \\
Erythroxylum subsessile & 0,020 & 0,129 & 0,000 & 0,007 & 0,003 & 0,064 & 0,201 & 0,07 \\
Vernonia fruticulosa & 0,020 & 0,129 & 0,000 & 0,000 & 0,003 & 0,064 & 0,195 & 0,07 \\
\hline
\end{tabular}

Tabela 4. Parâmetros fitossociológicos das espécies amostradas na formação arbustiva aberta não inundável do Parque Estadual Paulo César Vinha, Guarapari, ES, Brasil, em ordem decrescente de Valor de Importância. FA: Frequência Absoluta. FR (\%)-(\%): Frequência relativa. DLA (ind.ha $\left.{ }^{-1}\right)$ : Densidade linear absoluta. DLR (\%)-(\%): Densidade linear relativa. CLA $\left(\mathrm{m}^{2} . \mathrm{ha}^{-1}\right)$ : Cobertura linear absoluta. CLR (\%): Cobertura linear relativa. VI: Valor de Importância. VIR (\%)-(\%): Valor de Importância relativo.

Table 4. Phytosociological parameters of species sampled in the non-flooded open shrub formation of the Parque Estadual Paulo César Vinha (State Park), Guarapari City, Espírito Santo State, Brazil, in descending order of Importance Value. FA: Absolute frequency. FR (\%)-(\%): Relative frequency. DLA (ind.ha $\left.{ }^{-1}\right)$ : Linear density absolute. DLR (\%)-(\%): Linear relative density. CLA $\left(\mathrm{m}^{2} \cdot \mathrm{ha}^{-1}\right)$ : Linear coverage absolute. CLR (\%)-(\%): Linear coverage relative. VI: Importance Value. VIR (\%)-(\%): Relative Importance Value.

\begin{tabular}{lcccccccc}
\hline \multirow{2}{*}{ Espécies } & \multicolumn{7}{c}{ Parâmetros } \\
\cline { 2 - 8 } & FA & FR(\%) & DLA & DLR(\%) & CLA & CLR(\%) & VI & VIR(\%) \\
\hline Protium icicariba & 0,510 & 4,775 & 0,079 & 4,775 & 0,258 & 19,817 & 29,368 & 9,79 \\
Marlierea neuwiediana & 0,744 & 6,972 & 0,115 & 6,972 & 0,132 & 10,160 & 24,104 & 8,03 \\
Renvoizea trinii & 0,602 & 5,635 & 0,093 & 5,635 & 0,156 & 12,014 & 23,284 & 7,76 \\
Smilax rufescens & 0,632 & 5,921 & 0,098 & 5,921 & 0,002 & 0,193 & 12,036 & 4,01 \\
Allagoptera arenaria & 0,438 & 4,107 & 0,068 & 4,107 & 0,047 & 3,653 & 11,867 & 3,96 \\
Anthurium parasiticum & 0,316 & 2,960 & 0,049 & 2,960 & 0,072 & 5,536 & 11,457 & 3,82 \\
Serjania salzmanniana & 0,357 & 3,342 & 0,055 & 3,342 & 0,012 & 0,921 & 7,607 & 2,54 \\
Ocotea notata & 0,224 & 2,101 & 0,034 & 2,101 & 0,036 & 2,802 & 7,005 & 2,34 \\
Myrciaria floribunda & 0,193 & 1,814 & 0,030 & 1,814 & 0,042 & 3,270 & 6,899 & 2,30 \\
Ouratea cuspidata & 0,316 & 2,960 & 0,049 & 2,960 & 0,011 & 0,883 & 6,805 & 2,27 \\
Chaetocarpus myrsinites & 0,163 & 1,528 & 0,025 & 1,528 & 0,048 & 3,715 & 6,772 & 2,26 \\
Pilosocereus arrabidae & 0,316 & 2,960 & 0,049 & 2,960 & 0,010 & 0,784 & 6,705 & 2,24 \\
Peplonia asteria & 0,336 & 3,151 & 0,052 & 3,151 & 0,000 & 0,052 & 6,356 & 2,12 \\
Struthanthus sp, & 0,336 & 3,151 & 0,052 & 3,151 & 0,000 & 0,040 & 6,343 & 2,11
\end{tabular}


Tabela 4 (continuação)

\begin{tabular}{|c|c|c|c|c|c|c|c|c|}
\hline \multirow{2}{*}{ Espécies } & \multicolumn{8}{|c|}{ Parâmetros } \\
\hline & FA & $\mathrm{FR}(\%)$ & DLA & $\operatorname{DLR}(\%)$ & CLA & CLR(\%) & VI & $\operatorname{VIR}(\%)$ \\
\hline Kielmeyera membranacea & 0,071 & 0,668 & 0,011 & 0,668 & 0,063 & 4,861 & 6,198 & 2,07 \\
\hline Passiflora alliacea & 0,326 & 3,056 & 0,050 & 3,056 & 0,000 & 0,009 & 6,122 & 2,04 \\
\hline Anthurium cleistanthum & 0,204 & 1,910 & 0,031 & 1,910 & 0,030 & 2,301 & 6,121 & 2,04 \\
\hline Cereus fernambucensis & 0,316 & 2,960 & 0,049 & 2,960 & 0,001 & 0,110 & 6,032 & 2,01 \\
\hline Coccoloba arborescens & 0,204 & 1,910 & 0,031 & 1,910 & 0,028 & 2,204 & 6,025 & 2,01 \\
\hline Cyperus tenuis & 0,275 & 2,578 & 0,042 & 2,578 & 0,008 & 0,636 & 5,794 & 1,93 \\
\hline Clusia spiritu-sanctensis & 0,163 & 1,528 & 0,025 & 1,528 & 0,028 & 2,162 & 5,218 & 1,74 \\
\hline Melanopsidium nigrum & 0,163 & 1,528 & 0,025 & 1,528 & 0,023 & 1,827 & 4,883 & 1,63 \\
\hline Rheedia brasiliensis & 0,163 & 1,528 & 0,025 & 1,528 & 0,015 & 1,220 & 4,276 & 1,43 \\
\hline Clusia hilariana & 0,163 & 1,528 & 0,025 & 1,528 & 0,014 & 1,144 & 4,200 & 1,40 \\
\hline Coccoloba confusa & 0,183 & 1,719 & 0,028 & 1,719 & 0,008 & 0,667 & 4,105 & 1,37 \\
\hline Lantana pohliana & 0,163 & 1,528 & 0,025 & 1,528 & 0,006 & 0,482 & 3,538 & 1,18 \\
\hline Baccharis reticularia & 0,153 & 1,432 & 0,023 & 1,432 & 0,005 & 0,398 & 3,263 & 1,09 \\
\hline Vriesea procera & 0,091 & 0,859 & 0,014 & 0,859 & 0,019 & 1,497 & 3,216 & 1,07 \\
\hline Evolvulus maximiliani & 0,163 & 1,528 & 0,025 & 1,528 & 0,001 & 0,107 & 3,163 & 1,05 \\
\hline Myrcia acuminatissima & 0,051 & 0,477 & 0,007 & 0,477 & 0,023 & 1,800 & 2,755 & 0,92 \\
\hline Passiflora haematostigma & 0,132 & 1,241 & 0,020 & 1,241 & 0,000 & 0,009 & 2,493 & 0,83 \\
\hline Malphighiaceae 1 & 0,071 & 0,668 & 0,011 & 0,668 & 0,011 & 0,866 & 2,204 & 0,73 \\
\hline Cyrtopodium sp, & 0,091 & 0,859 & 0,014 & 0,859 & 0,005 & 0,386 & 2,105 & 0,70 \\
\hline Epidendrum denticulatum & 0,102 & 0,955 & 0,015 & 0,955 & 0,001 & 0,146 & 2,056 & 0,69 \\
\hline Microtea paniculata & 0,102 & 0,955 & 0,015 & 0,955 & 0,000 & 0,002 & 1,912 & 0,64 \\
\hline Tillandsia gardneri & 0,081 & 0,764 & 0,012 & 0,764 & 0,004 & 0,348 & 1,876 & 0,63 \\
\hline Manilkara subsericea & 0,061 & 0,573 & 0,009 & 0,573 & 0,006 & 0,465 & 1,611 & 0,54 \\
\hline Paullinia weinmanniaefolia & 0,081 & 0,764 & 0,012 & 0,764 & 0,000 & 0,051 & 1,579 & 0,53 \\
\hline Maytenus obtusifolia & 0,081 & 0,764 & 0,012 & 0,764 & 0,000 & 0,039 & 1,567 & 0,52 \\
\hline Cuphea flava & 0,081 & 0,764 & 0,012 & 0,764 & 0,000 & 0,014 & 1,542 & 0,51 \\
\hline Erythroxylum subrotundum & 0,061 & 0,573 & 0,009 & 0,573 & 0,004 & 0,312 & 1,459 & 0,49 \\
\hline Andira nitida & 0,071 & 0,668 & 0,011 & 0,668 & 0,000 & 0,068 & 1,405 & 0,47 \\
\hline Tocoyena bullata & 0,051 & 0,477 & 0,007 & 0,477 & 0,005 & 0,445 & 1,400 & 0,47 \\
\hline Aechmea lingulata & 0,010 & 0,095 & 0,001 & 0,095 & 0,015 & 1,198 & 1,389 & 0,46 \\
\hline Aechmea nudicaulis & 0,040 & 0,382 & 0,006 & 0,382 & 0,007 & 0,580 & 1,344 & 0,45 \\
\hline Polypodium brasiliense & 0,051 & 0,477 & 0,007 & 0,477 & 0,003 & 0,258 & 1,213 & 0,40 \\
\hline Emmeorhiza umbellata & 0,061 & 0,573 & 0,009 & 0,573 & 0,000 & 0,024 & 1,170 & 0,39 \\
\hline Passiflora mucronata & 0,061 & 0,573 & 0,009 & 0,573 & 0,000 & 0,004 & 1,151 & 0,38 \\
\hline Byrsonima sericea & 0,040 & 0,382 & 0,006 & 0,382 & 0,005 & 0,381 & 1,145 & 0,38 \\
\hline Stigmaphyllon paralias & 0,051 & 0,477 & 0,007 & 0,477 & 0,001 & 0,135 & 1,090 & 0,36 \\
\hline Passiflora galbana & 0,051 & 0,477 & 0,007 & 0,477 & 0,000 & 0,058 & 1,013 & 0,34 \\
\hline Sebastiania glandulosa & 0,040 & 0,382 & 0,006 & 0,382 & 0,000 & 0,071 & 0,835 & 0,28 \\
\hline Humiria balsamifera & 0,010 & 0,095 & 0,001 & 0,095 & 0,007 & 0,566 & 0,757 & 0,25 \\
\hline Microgramma vacciniifolia & 0,020 & 0,191 & 0,003 & 0,191 & 0,004 & 0,365 & 0,747 & 0,25 \\
\hline
\end{tabular}


Tabela 4 (continuação)

\begin{tabular}{lcccccccc}
\hline \multirow{2}{*}{ Espécies } & \multicolumn{7}{c}{ Parâmetros } \\
\cline { 2 - 8 } & FA & FR(\%) & DLA & DLR(\%) & CLA & CLR(\%) & VI & VIR(\%) \\
\hline Chiococca alba & 0,030 & 0,286 & 0,004 & 0,286 & 0,000 & 0,049 & 0,623 & 0,21 \\
Marsdenia montana & 0,030 & 0,286 & 0,004 & 0,286 & 0,000 & 0,003 & 0,576 & 0,19 \\
Habenaria leptoceras & 0,020 & 0,191 & 0,003 & 0,191 & 0,002 & 0,149 & 0,531 & 0,18 \\
Stylosanthes viscosa & 0,020 & 0,191 & 0,003 & 0,191 & 0,001 & 0,093 & 0,475 & 0,16 \\
Clusiaceae 1 & 0,010 & 0,095 & 0,001 & 0,095 & 0,003 & 0,247 & 0,438 & 0,15 \\
Chamaecrista cytisoides & 0,010 & 0,095 & 0,001 & 0,095 & 0,002 & 0,153 & 0,344 & 0,11 \\
Vanilla chamissonis & 0,010 & 0,095 & 0,001 & 0,095 & 0,001 & 0,112 & 0,303 & 0,10 \\
Malpighiaceae 2 & 0,010 & 0,095 & 0,001 & 0,095 & 0,001 & 0,075 & 0,266 & 0,09 \\
Salzmannia nitida & 0,010 & 0,095 & 0,001 & 0,095 & 0,001 & 0,074 & 0,265 & 0,09 \\
Bromeliaceae 1 & 0,010 & 0,095 & 0,001 & 0,095 & 0,000 & 0,058 & 0,249 & 0,08 \\
Eltroplectris sp. & 0,010 & 0,095 & 0,001 & 0,095 & 0,000 & 0,012 & 0,203 & 0,07 \\
Tillandsia stricta & 0,010 & 0,095 & 0,001 & 0,095 & 0,000 & 0,011 & 0,202 & 0,07 \\
Malpighiaceae 3 & 0,010 & 0,095 & 0,001 & 0,095 & 0,000 & 0,020 & 0,211 & 0,07 \\
Acosmium bijugum & 0,010 & 0,095 & 0,001 & 0,095 & 0,000 & 0,001 & 0,192 & 0,06 \\
\hline
\end{tabular}

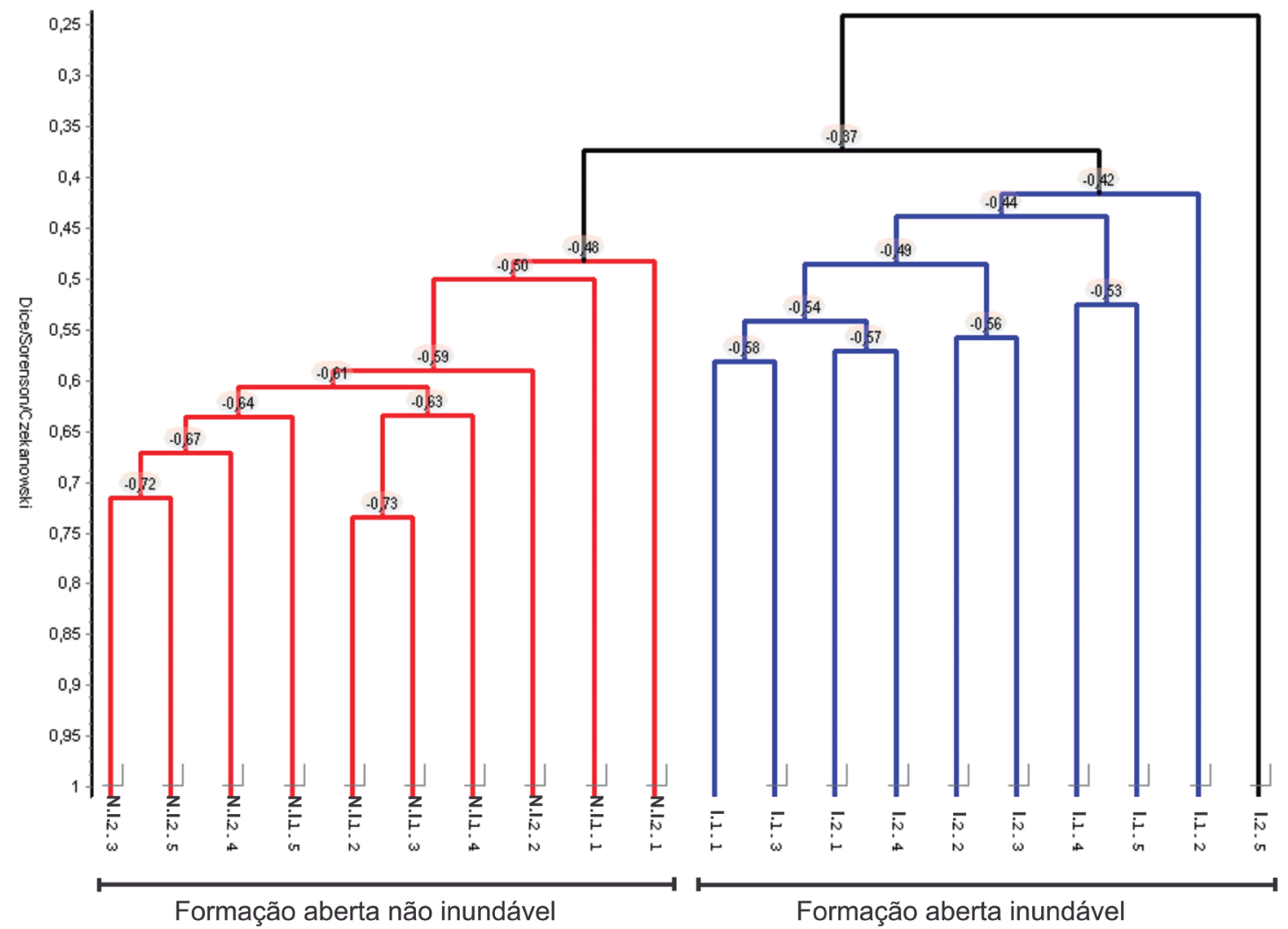

Figura 2. Dendrograma de similaridade florística entre as parcelas amostradas nas formações arbustivas abertas inundável e não inundável do Parque Estadual Paulo César Vinha, Guarapari, ES, Brasil.

Figure 2. Floristic similarity dendrogram between the plots sampled in the flooded and non-flooded open shrub formations of the Parque Estadual Paulo César Vinha (State Park), Guarapari City, Espírito Santo State, Brazil. 
de Jurubatiba, Rio de Janeiro, inclusive para a FAAI do Rio de Janeiro (Montezuma \& Araújo 2007). Vriesea procera também é bem representada nas duas regiões, com valores de frequência relativa e densidade linear relativa mais altos que $P$. icicariba, porém seu menor porte e cobertura resultaram no seu menor VI.

Uma das características da formação arbustiva aberta não inundável é a presença de um anel de bromélias que circunda as moitas, representada principalmente por $V$. procera (Pereira 1990). Em Matinhos no Paraná esta espécie é característica de áreas sujeitas a inundações e é importante na composição da planície litorânea na Ilha do Mel (Kersten \& Silva 2001). Para a restinga de Jurubatiba, $V$. procera não chega a figurar entre as 10 espécies mais representativas da região (Cogliatti-Carvalho et al. 2001). Esses dados indicam que apesar de ser muito presente na FAANI no PEPCV, em outras regiões $V$. procera ocorre em ambientes inundáveis, retratando distinção na sua ocupação ao longo do litoral brasileiro. Outra espécie de Bromeliaceae em posição de destaque foi Tillandsia stricta, que é a espécie do gênero com maior VI dentre as bromélias da restinga de Jurubatiba, sendo que as três espécies de Tillandsia apresentaram as mesmas posições quanto ao VI em Jurubatiba (Cogliatti-Carvalho et al. 2001).

Allagoptera arenaria está entre as 10 espécies com maior VI nas duas regiões, sendo a nona na FAAI e a terceira na FAANI. Em Jurubatiba, essa espécie apresentou o maior VI da região, enquanto em Linhares, Espírito Santo, encontra-se com os mais altos valores de frequência, densidade e, principalmente, de cobertura (Pereira et al. 2004). A. arenaria também é a principal espécie na formação arbustiva de Palmae na Restinga de Marambaia no Rio de Janeiro (Menezes $\&$ Araujo 2004). Em três áreas estudadas na Praia do Peró em Cabo Frio (Rio de Janeiro), A. arenaria está entre as espécies com maiores VI (Cordeiro 2005).

Dentre as espécies exclusivas, Renvoizea trinii ocorreu na FAANI, presente em elevado número na borda da moita, podendo ser útil para reconhecimento dessa fitofisionomia. Para uma restinga em Linhares, $R$. trinii ocupou a oitava posição em Valor de Importância para formações abertas (Pereira \& Assis 2004). Para a FAAI, Gaylussacia brasiliensis é a espécie exclusiva com maior VI, quarta posição, sendo a mais indicada para reconhecimento dessa fitofisionomia. Na FAAI da restinga de Jurubatiba, G. brasiliensis se apresenta apenas em $28^{\circ}$ em Valor de Importância, podendo ser encontrada isoladamente no entre moitas com porte arbustivo (Montezuma \& Araújo 2007).
Perante o exposto, foi possível caracterizar florística e estruturalmente duas fitofisionomias arbustivas abertas (inundável e não inundável) da restinga do Espírito Santo com baixa similaridade florística entre elas. As diferenças florísticas verificadas em cada formação parecem ter relação direta com o regime de disponibilidade hídrica no solo a que estão submetidas, no entanto, deve-se ressaltar a plasticidade que determinadas espécies apresentam (ex. Vriesea procera), podendo ser comum em ambientes inundáveis ou não. Na FAAI houve maior riqueza de espécies vegetais e maior porte dos indivíduos, distribuídas em moitas com maior área e volume. Apesar da elevada distinção florística, Protium icicariba apresentou-se como a principal espécie em Valor de Importância em ambas às áreas. Em relação às espécies exclusivas, Gaylussacia brasiliensis e Renvoizea trinii são as espécies mais bem representadas, respectivamente na FAAI e FAANI, o que as coloca como espécies indicadoras dessas fitofisionomias.

\section{Agradecimentos}

Os autores agradecem aos pesquisadores Oberdan José Pereira e Rodrigo Theófilo Valadares pelo auxílio na identificação geral das espécies vegetais; e ao pesquisador Marcos Eduardo Guerra Sobral pela identificação das espécies da família Myrtaceae. Agradece-se também a direção do Parque Estadual Paulo César Vinha que deu amplo acesso a área de estudo, o que foi fundamental para a realização das coletas e desenvolvimento da pesquisa.

\section{Literatura citada}

Almeida, J.R., Bezerra, E., Olivo, M.A., Araújo, E.L. \& Zickel, C.S. 2009. Caracterização da vegetação de restinga da RPPN de Maracaípe, PE, Brasil, com base na fisionomia, flora, nutrientes do solo e lençol freático. Acta Botanica Brasilica 23: 36-48.

APG IV. 2016. An update of the Angiosperm Phylogeny Group classification for the orders and families of flowering plants: APG IV. Botanical Journal of the Linnean Society 181: 1-20.

Araújo, D.S.D. \& Henriques R.P.B. 1984. Análise florística das Restingas do Estado do Rio de Janeiro. In: L.D. Lacerda, D.S.D. Araujo, R. Cerqueira \& B. Turcq (eds.). Restingas: origem, estrutura e Processos. CEUFF, Niterói, pp. 159-193.

Assis A.M., Pereira O.J. \& Thomaz L.D. 2004. Fitossociologia de uma floresta de restinga no Parque Estadual Paulo César Vinha, Setiba, município de Guarapari (ES). Acta Botânica Brasílica 27: 349-361. 
Assumpção, J. \& Nascimento, M.T. 2000. Estrutura e composição florística de quatro formações vegetais de restinga no complexo lagunar Grussaí/Iquipari, São João da Barra, RJ, Brasil. Acta Botânica Brasílica 14: 301-315.

Cogliatti-Carvalho, L.F., A.F.N., Rocha, C.F.D. \& Van Sluys M. 2001. Variação na estrutura e na composição de Bromeliaceae em cinco zonas de restinga no Parque Nacional da Restinga de Jurubatiba, Macaé, RJ. Revista Brasileira de Botânica 24: 1-9.

Cordeiro, S.Z. 2005. Composição e distribuição da vegetação herbácea em três áreas com fisionomias distintas na Praia do Peró, Cabo Frio, RJ, Brasil. Acta Botânica Brasílica 19: 679-693.

Coutinho, C.L. 2006. O conceito de bioma. Acta Botânica Brasílica 20: 13-23.

Fidalgo, O. \& Bononi, V.L.R. 1989. Técnicas de coleta, preservação e herborização de material botânico, Instituto de Botânica. Instituto de Botânica, São Paulo.

Giaretta, A., Menezes, L.F.T. \& Pereira, O.J. 2013. Structure and floristic pattern of a restinga in southeastern Brazil. Acta Botanica Brasilica 27: 87-107.

Kersten, R.A. \& Silva, S.M. 2001. Composição florística e estrutura do componente epifítico vascular em floresta da planície litorânea na Ilha do Mel, Paraná, Brasil. Revista Brasileira de Botânica 24: 213-226.

Köppen, W. 1948. Climatologia: com um estúdio de los climas de la tierra. Laboratory of Climatology, New Jersey.

Magnago, L.F.S., Martins, S.V. \& Pereira O.J. 2011. Heterogeneidade florística das fitocenoses de restingas nos estados do Rio de Janeiro e Espírito Santo, Brasil. Revista Árvore 35: 245-254.

Magurran, A.E. 1988. Ecological diversity and its measurement. Princeton University Press, Princeton.

Menezes, L.F.T. \& Araujo, D.S.D. 2004. Regeneração e riqueza da formação arbustiva de Palmae em uma consequência pós-fogo na Restinga da Marambaia, Rio de Janeiro, RJ, Brasil. Acta Botânica Brasílica 18: 771-780.

Montezuma, R.C.M. \& Araújo, D.S.D. 2007. Estrutura da vegetação de uma restinga arbustiva inundável no Parque Nacional da Restinga de Jurubatiba, Rio de Janeiro. Pesquisas: Botânica 58: 157-176.

Mueller-Dombois, D. \& Ellenberg, H. 1974. Aims and methods of vegetation ecology. John Wiley \& Sons, New York.

Passamani, M. \& Fraga, C.N. 2005. Conservação da biodiversidade da Mata Atlântica no Estado do Espírito Santo. Disponível em http://www.biodiversitas.org. br/listas-mg/ES-especies-ameacadas.pdf (acesso em 10-IV-2019).
Pereira, O.J. 2003. Restinga: origem, estrutura e diversidade. In: M.A.G. Jardim, M.N.C. Bastos \& J.U.M. Santos (eds.). Anais do $54^{\circ}$ Congresso Nacional de Botânica. Sociedade Brasileira de Botânica, Belém, pp. 177-179.

Pereira, O.J. 1990. Caracterização fitofisionômica da restinga de Setiba. Guarapari, E.S. In: S. Watanabe (ed.). Anais do II Simpósio Ecossistemas da Costa Sul-Sudeste. ACIESP, Águas de Lindóia, pp. 207-219.

Pereira, O.J. \& Assis, A.M. 2004. Fitossociologia da vegetação arbustiva fechada inundável de Restinga no município de Linhares (ES). In: ACIESP (ed.). Anais do Simpósio de Ecossistemas Brasileiros: Patrimônio Ameaçado. ACIESP, São Paulo, pp. 407-413.

Pereira, O.J. \& Assis, A.M. 2000. Florística da restinga de Camburi, Victória, ES. Acta Botânica Brasílica 14: 99-111.

Pereira, O.J. \& Zambom, O. 1998. Composição florística da restinga de Interlagos, Vila Velha (ES). In: ACIESP (ed.). Anais do IV Simpósio de Ecossistemas Brasileiros. ACIESP, Águas de Lindóia, pp. 129-139.

Pereira, M.C.A., Cordeiro, S.Z. \& Araujo, D.S.D. 2004. Estrutura do estrato herbáceo na formação aberta de Clusia do Parque Nacional da Restinga de Jurubatiba, RJ, Brasil. Acta Botânica Brasílica 18: 677-687.

Pereira, O.J., Thomaz, L.D. \& Araujo, D.S.D. 1992. Fitossociologia da vegetação de antedunas da restinga de Setiba/Guarapari e em Interlagos/Vila Velha, ES. Boletim Museu Biologia Mello Leitão 1: 65-75.

Ribas, L.A., Hay, J.D. \& Caldas-Soares, J.F. 1993. Moitas de restinga: ilhas ecológicas? In: ACIESP (ed.). Anais do III Simpósio de Ecossistemas da Costa Brasileira. ACIESP, São Paulo, pp. 79-88.

Sá, C.F.C. 1992. A vegetação da restinga de Ipitangas, Reserva Ecológica Estadual de Jacarepiá, Saquarema (RJ): Fisionomia e Listagem de Angiospermas. Arquivos do Jardim Botânico do Rio de Janeiro 31: 87-102.

Scherer, A., Maraschin-Silva, F. \& Baptista, L.R.M. 2005. Florística e estrutura do componente arbóreo de matas de Restinga arenosa no Parque Estadual de Itapuã, RS, Brasil. Acta Botânica Brasílica 19: 717-726.

Shepherd, G.J. 1996. Fitopac 1: manual do usuário. UNICAMP, Campinas.

Suguio, K. \& Martin, L. 1993. Geomorfologia das restingas. In: ACIESP (ed.). Anais do III Simpósio de Ecossistemas Brasileiros. ACIESP, São Paulo, pp. 185-205.

Ule, E. 1901. Die vegetation von Cabo Frio an der Kusten von Brasilien. Botanische Jahrbiicher für Systematik 28: 511-528.

Young, D.R., Shao, G. \& Porter, J.H. 1995. Spatial and temporal growth dynamics of barrier island shrub thickets. American Journal of Botany 82: 638-645. 